\title{
Devising and Demonstrating an Extreme Weather Risk Indicator for Use in Transportation Systems
}

\author{
Pekka Leviäkangas, Riitta Molarius, Ville Könönen, \\ Zulkarnain Zulkarnain, and Anna-Maija Hietajärvi
}

\begin{abstract}
This paper describes a novel risk indicator for extreme weather risks for use in transportation systems. The risk indicator is applied to the European transportation system indicating and ranking the risks for the 27 member states of the European Union (EU-27). The paper starts with definitions of hazards, vulnerability, and risk, based on relevant literature, and then operationalizes the risk, hazard, and vulnerability with the help of EU-27 data. Finally, the paper discusses the extreme weather risk indicator (EWRI) and evaluates its applicability and limitations. The risk indicator is a relative indicator: it should be viewed and treated as a ranking system. The devised indicator is able to assist decision makers at national and state as well as international and federal levels in the prioritization of extreme weather risks within their jurisdiction. The overall approach of EWRI is based on mainstream risk and vulnerability assessment research, following for the most part the existing conceptual models. The novelty of EWRI lies in its application area (transportation) and wide use of both empirical and statistical data. EWRI was used to assess the hazards, vulnerabilities, and risks of extreme weather for the EU-27, but nothing hinders its application, either in this form or a modified form, in other contexts.
\end{abstract}

This paper describes a novel risk indicator for extreme weather risks for use in transportation systems. The research has been conducted in the EWENT project (Extreme Weather Impacts on European Networks of Transport; http://ewent.vtt.fi/) and the extreme weather risk indicator (EWRI) is one of the key results.

A number of risk, hazard, and vulnerability indicators have been developed for contingent purposes, and the indication system presented in this paper follows the mainstream research on risk and vulnerability assessment. However, the risk indicator presented in this paper is, to the authors' knowledge, unique. The risk indicator is applied to the European transportation system, indicating and ranking the risks for the 27 member states of the European Union (EU-27).

P. Leviäkangas, Department of Industrial Engineering and Management, University of Oulu, P.O. Box 4610, 90014 Oulu, Finland. R. Molarius, VTT Technical Research Center of Finland, P.O. Box 1300, 33101 Tampere, Finland. V. Könönen, Z. Zulkarnain, and A.-M. Hietajärvi, VTT Technical Research Center of Finland, P.O. Box 1100, 90571 Oulu, Finland. Corresponding author: P. Leviäkangas, pekka.leviakangas@oulu.fi.

Transportation Research Record: Journal of the Transportation Research Board, No. 2329, Transportation Research Board of the National Academies, Washington, D.C., 2013, pp. 45-53.

DOI: $10.3141 / 2329-06$
Because of the various climatic patterns, different regions of Europe are affected by different weather extremes. A map of the European climate regions was created by the Finnish Meteorological Institute for the EWENT project to facilitate the assessment of impacts and consequences of extreme weather phenomena in Europe (1). On the basis of the frequency and probability analysis of the selected climatic extremes, six main climate regions were differentiated: Northern European, Temperate Eastern European, Temperate Central European, Mediterranean, Mountainous, and Oceanic regions (Figure 1).

This paper describes EWRI metrics and applies it to the 27 member states of the European Union. The tool and the results may be applied to other contexts, such as the states of the United States or countries of any particular region. Furthermore, with little effort the same type of risk assessment is possible within more restricted geographical areas (e.g., counties or municipalities within a state or country).

This paper begins with definitions of hazards, vulnerability, and risk, based on relevant literature, and then operationalizes the risk, hazard, and vulnerability with the help of EU-27 data. Finally, it discusses the EWRI tool, evaluating its applicability and limitations.

\section{VULNERABILITY OF TRANSPORTATION NETWORKS: LITERATURE STUDY}

A number of studies exist related to vulnerability in transportation, each with its own approach. Taylor and D'Este proposed a methodology for obtaining the vulnerability of each component of the network on the national level (2). They defined some main issues to be considered, such as link criticality, system performance, traffic management aspects, and demand. From this starting point they developed a methodology for study of vulnerability in transportation networks and infrastructure. They defined vulnerability as follows:

- A network node is vulnerable if loss (or considerable degradation) of a small number of links significantly diminishes the accessibility of the node, as measured by a standard indicator of accessibility.

- A network link is critical if loss (or considerable degradation) of the link significantly diminishes the accessibility of the network or of particular nodes, as measured by a standard indicator of accessibility.

Sohn et al. produced analyses on the economic impact of an earthquake on a transportation network (3). They assessed two aspects of 


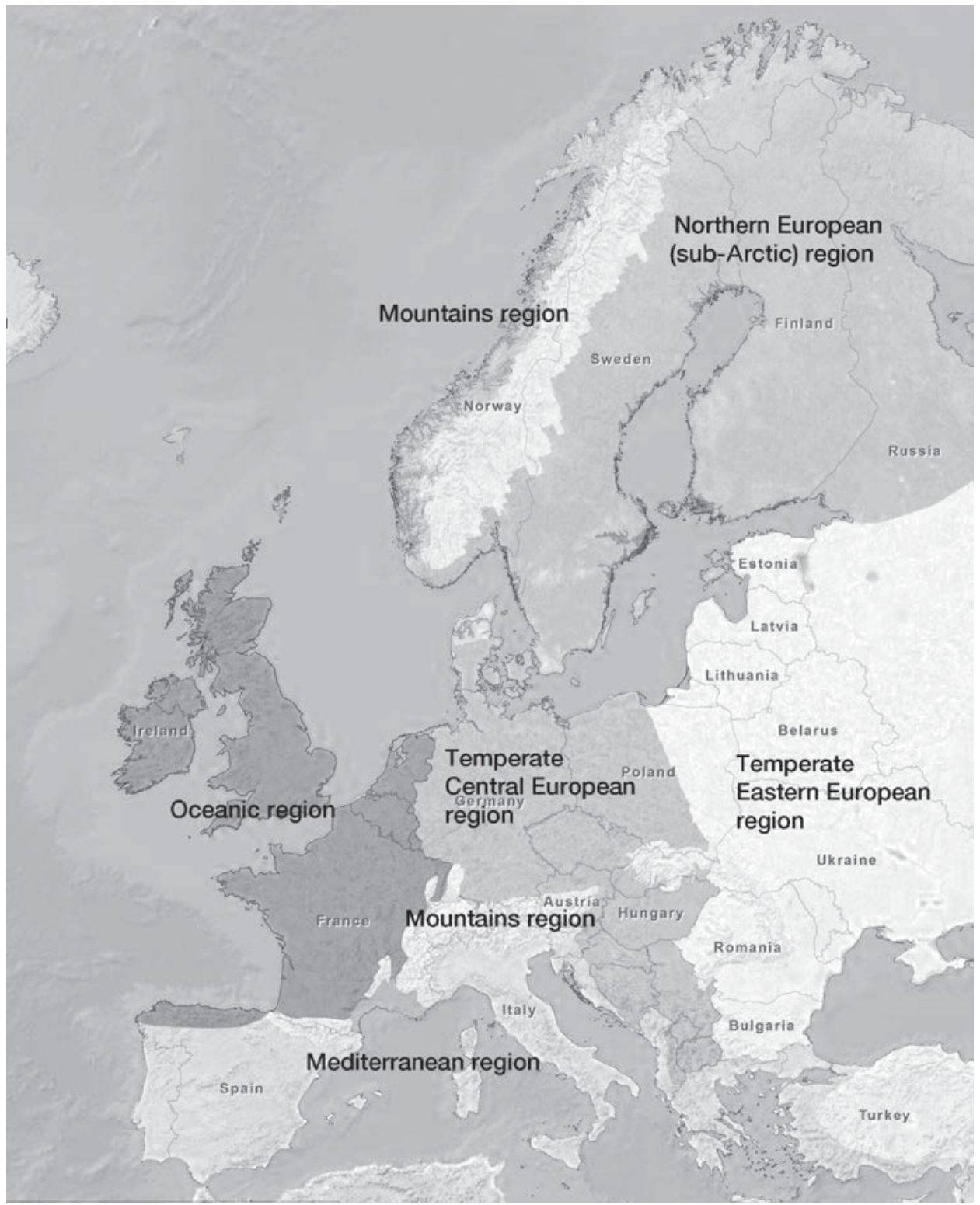

FIGURE 1 Climate regions of Europe.

cost: final demand loss and transport cost increase. They found that the links with greater physical disruption are not always the ones exhibiting greater economic damage.

Schulz studied German road networks to find the most critical roads (4). There were two different approaches. The first used information only on traffic load, while the other used more complicated transport modeling. It was noticed that the critical roads identified were not the same with these two methods. The first approach mainly highlighted autobahns as critical roads, while the more complicated approach also considered some sections of federal roads to be critical.

Nicholls et al. studied the port cities and their vulnerability to climate extremes (5). The methodology adopted was based on determining the numbers of people who would be exposed to extreme water levels, which could then be related to the potential economic assets exposed within the city. The relative exposure to wind damage was calculated by weighting the present-day wind damage hazard, for tropical and extra-tropical cyclones, by the total city population. In this study the linkage between exposure and the risk of impact depended on flood protection measures. Cities in richer countries have better protection levels than those in the developing world and also have access to greater resources for disaster recovery, although the asset losses in absolute terms may be much higher.

Riccardo et al. assessed the criticality of transportation networks in the WEATHER project (http://www.weather-project.eu/weather/ index.php) (6). The authors created a definition and differentiation between vulnerability and criticality for a transportation network. Vulnerability of a network element is defined as its physical sensitivity to extreme events and indicates which parts of a network are the most sensitive. Criticality of a network element, however, is a term associated with the entire network performance, indicating the relative importance of the independent network components, road sections (links) and intersections (nodes), to overall network 
efficiency. Criticality indicates which parts of a network are the most important and critical for the regular function of the network.

\section{VULNERABILITY AND RISK: A CONCEPTUAL VIEW}

The concept of risk has been defined as "effect of uncertainty on objectives" (7). This conceptualization highlights that some objects are affected, positively or negatively, rather than it being a question of "something happens." This means that one must analyze the likelihoods and consequences of the impacts, not the initial events (8).

Risk is most often defined as a chance that an undesirable event will occur and the consequences of its possible outcomes $(9,10)$. However, in some cases risk has been defined as being equal to consequences: for example, FAR (fatal accident rates) values as the expected number of fatalities per 100 million exposed hours. Risk analysis is used to verify that the risk acceptance criteria are met and to decide on the need for risk-reducing measures $(11,12)$. In other cases, risk has been defined as being equal to probability $(13,14)$. This definition is common, for example, in insurance and the nuclear industry, where the main focus of risk management is to diminish the probability of failures - albeit with implicit thought of impacts and consequences.

Mathematically, risk $R$ is most often defined as a function of probability $P$ and consequences $C$ :

$$
R=f(P, C)
$$

However, as mentioned before, risk can also be understood as the probability of a harmful event, especially when this event has been specified in advance.

$R=f(P)$

It has been highlighted that there is no single inclusive definition for the term "vulnerability" because of its varying use in different policy contexts (15). Very often, vulnerability refers to specific vulnerable situations that can cause harm to the existing systems, such as critical infrastructures.

The concepts of risk and vulnerability have been associated with each other in several ways. In some cases they are understood to be almost uniform. For example, Cutter defined vulnerability as "the likelihood that an individual or group will be exposed to and adversely affected by a hazard" (16).

Moreover, one mathematical expression of risk is

$R=f(H, V)$

where $H$ is hazard and $V$ is vulnerability (17). This is justified by the explanation that hazards are only defined as potentially damaging phenomena when a vulnerable object is exposed to the hazard and the potential for loss occurs (18).

Alexander defined this connection in the context of natural disasters by introducing the concept of total risk (TR) (19). In the equation, the elements at risk might be population, built environment, economic activities, and so forth.

$\mathrm{TR}=\left(\sum\right.$ elements at risk $) \times$ hazard $\times$ vulnerability
Walker et al. concluded almost the same result by stating that risk can be expressed by the notation "risk $=$ hazards $\times$ vulnerability" (18). Villagrán stated that risk is a function of hazard, vulnerability, and deficiencies in preparedness (20).

risk $=$ hazard $\times$ vulnerability $\times$ deficiencies in preparedness

Dilley et al. (21) expressed that

risk $=$ hazard $\times$ exposure $\times$ vulnerability

All these conceptual models suggest that risk is inseparable from vulnerability, and further concepts such as hazards and exposure are an elemental part of risk assessment. Therefore, the Disaster Reduction Institute has formulated vulnerability as a function of exposure, susceptibility, and coping capacity (22).

vulnerability $=\frac{\text { exposure } \times \text { susceptibility }}{\text { coping capacity }}$

The Center for European Policy Studies states that assessing critical infrastructure vulnerability means "a systematic examination of the characteristics of an installation, system, asset, application, or its dependencies, to identify vulnerabilities" (23).

Cutter et al. used a "hazards-of-place" model of vulnerability to explore social vulnerability in the context of natural hazards, where levels of risk and levels of mitigation are combined to produce hazard potential (24). This hazard potential is then filtered by geographic and social variables to produce social vulnerability. Social vulnerability and hazard potential thereby produce overall vulnerability of place. Cutter et al. further created a social vulnerability indicator, SoVI, which comprised a multitude of indicators expressed by data from the U.S. Census. SoVI results were mapped by county to create a patchwork of comparative vulnerability indication across the United States. As a result, most U.S. counties were found to have moderate social vulnerability; areas of high social vulnerability were most frequent in the southern parts of the United States.

Füssel listed different characteristics of vulnerability depending on whether there is a question of climate change or natural hazards (Table 1) (15). Finally, de León noticed that there are three

TABLE 1 Characteristics of Vulnerability Assessments (15)

\begin{tabular}{|c|c|c|}
\hline Characteristic & Natural Hazards & Climate Change \\
\hline \multicolumn{3}{|l|}{ Hazard } \\
\hline Temporal & Discrete events & $\begin{array}{l}\text { Discrete and continuous } \\
\text { events }\end{array}$ \\
\hline Dynamics & Stationary & Nonstationary \\
\hline Spatial scope & Regional & Global but heterogeneous \\
\hline Uncertainty & Low to medium & Medium to very high \\
\hline Attribution & Natural variability & Natural and anthropogenic \\
\hline $\begin{array}{l}\text { Systems of } \\
\text { concern }\end{array}$ & $\begin{array}{l}\text { Social systems and built } \\
\text { infrastructures }\end{array}$ & All systems \\
\hline System view & Static & Dynamic and adaptive \\
\hline $\begin{array}{l}\text { Targets for risk } \\
\text { reduction }\end{array}$ & $\begin{array}{l}\text { Exposure to hazards and } \\
\text { internal vulnerability }\end{array}$ & $\begin{array}{l}\text { Magnitude of hazards and } \\
\text { internal vulnerability }\end{array}$ \\
\hline $\begin{array}{l}\text { Analytical } \\
\text { function }\end{array}$ & Normative & Positive and normative \\
\hline
\end{tabular}


discourses regarding vulnerability: (a) vulnerability refers to a particular condition or state of a system before an event triggers a disaster, $(b)$ vulnerability means a direct consequence of the exposure to a hazard, and $(c)$ vulnerability equals the probability or possibility of an outcome of the system when exposed to a hazard that is linked to fatalities and economic and social losses (17).

\section{RISK INDICATION AND RANKING SYSTEM IN EWENT PROJECT}

Risk has been defined in the EWENT project as a product of natural hazard and vulnerability. The following sections depict the vulnerability indicator used in the study, then briefly the hazard indicator, and finally the risk indicator.

\section{Vulnerability Indicator}

Vulnerability is defined, following the practice of the Disaster Reduction Institute, as a function of exposure $(E)$, susceptibility $(S)$, and coping capacity (CC).

$V=f\left(\frac{(\text { exposure } \times \text { susceptibility })}{\text { coping capacity }}\right)=E \times \frac{S}{\mathrm{CC}}$

The vulnerability of the system consists of exposure, susceptibility, and coping capacity. When calculating vulnerability indicator $V$, the following statistics and data sets were used:

\section{Exposure [E]}

- Traffic performance (25). The more traffic performance there is, the more there are exposed transportation system users in volume and geographical coverage, and the more likely that there is less infrastructure capacity to "absorb" the impacts and consequences and that there are parts of the system that are exposed. The performance describes the geographical exposure (long distances, vast network), whereas the population density counterbalances the urbanization effect (more people are exposed).

- Population density (25). The more population is located in a certain area, the more inhabitants are exposed; furthermore, population density directly refers to urbanization, and the urban areas are more likely to be exposed to negative impacts by population numbers and number of modes exposed.

\section{Susceptibility [S]}

Infrastructure quality indicator. The indicator measures executives' perceptions of general infrastructure in their respective countries. Executives grade, on a scale from 1 to 7 , whether general infrastructure in their country is poorly developed (1) or among the best in the world (7). This indicator is calculated for The Global Competitiveness Report 2011-2012 (26).

\section{Coping Capacity [CC]}

Purchasing power parity adjusted per capita gross domestic product (GDP) measured in current U.S. dollars for differences in purchasing power parity (PPP) is applied as a robust indicator of the economic capability of the country to face and overcome negative consequences of extreme weather. In short, it describes economic resilience. These data are obtained from the IMF World Economic Outlook (27). The inverse number of coping capacity (i.e., as a multiplier, not as a divisor) was used in this study.

Each of the indicators was classified in quartiles within the EU-27. The best quartile was given values of 0.25 , the second 0.5 , the third 0.75 , and the poorest quartile 1.0. In this way, the larger the given indicator value, the more vulnerable is the country. This study used discrete quartile steps to overcome some theoretical difficulties of scaling for the first quartile, while for the second quartile it was assessed that such robust indicators should be treated and classified in an equally robust manner. The table below gives an interpretation of the vulnerability scaling.

$\begin{array}{ll}\text { Quartile } & \text { Description of Ranking } \\ \text { Highest quartile }=1.00 & \text { High vulnerability } \\ \text { Upper-midquartile }=0.75 & \text { Moderately high vulnerability } \\ \text { Lower-midquartile }=0.50 & \text { Moderately low vulnerability } \\ \text { Lowest quartile }=0.25 & \text { Low vulnerability }\end{array}$

The following discussion is an example calculation of Finland's vulnerability. Finland's vulnerability for road system and passenger transportation was built on its exposure, susceptibility, and coping capacity as follows:

$$
\begin{aligned}
E & =\text { traffic performance }\left(\begin{array}{l}
\text { million passenger } \mathrm{km} \\
\times \text { population density }\left(\frac{\text { persons }}{\mathrm{km}^{2}}\right)
\end{array}\right) \\
& =0.50 \times 0.25=0.125
\end{aligned}
$$

Finland has long distances and a vastly stretched road network, which makes it vulnerable because of geographical exposure; long-distance trips are also common, increasing passenger kilometers. However, population density is very low, and fewer people are exposed to harmful weather. The former parameter belongs to the "second best" quartile in EU-27 and the latter to the "best" quartile. (The tonne-kilometer was used for the freight system.)

Finland has a relatively good road infrastructure, which positions it in the best quartile for road infrastructures in EU-27.

$S=$ infrastructure quality indicator of 5.8

$($ on the scale of 1 to 7$)=0.25$

Finland has a relatively high GDP per capita, which entitles it to the second best quartile within EU-27.

$\mathrm{CC}_{\text {inv }}=$ GDP per capita $(\mathrm{PPP})=0.5$ (inversely ranked $)$

The vulnerability indicator for Finland's road passenger system is then

$V_{r, p}=0.125 \times 0.25 \times 0.5 \approx 0.0156$

For Bulgaria, for example, the corresponding indicator gives a value of $V_{r, p}=0.0469$; this is a clearly higher vulnerability indicator value. The higher the indicator values, the more vulnerable the country is expected to be. 


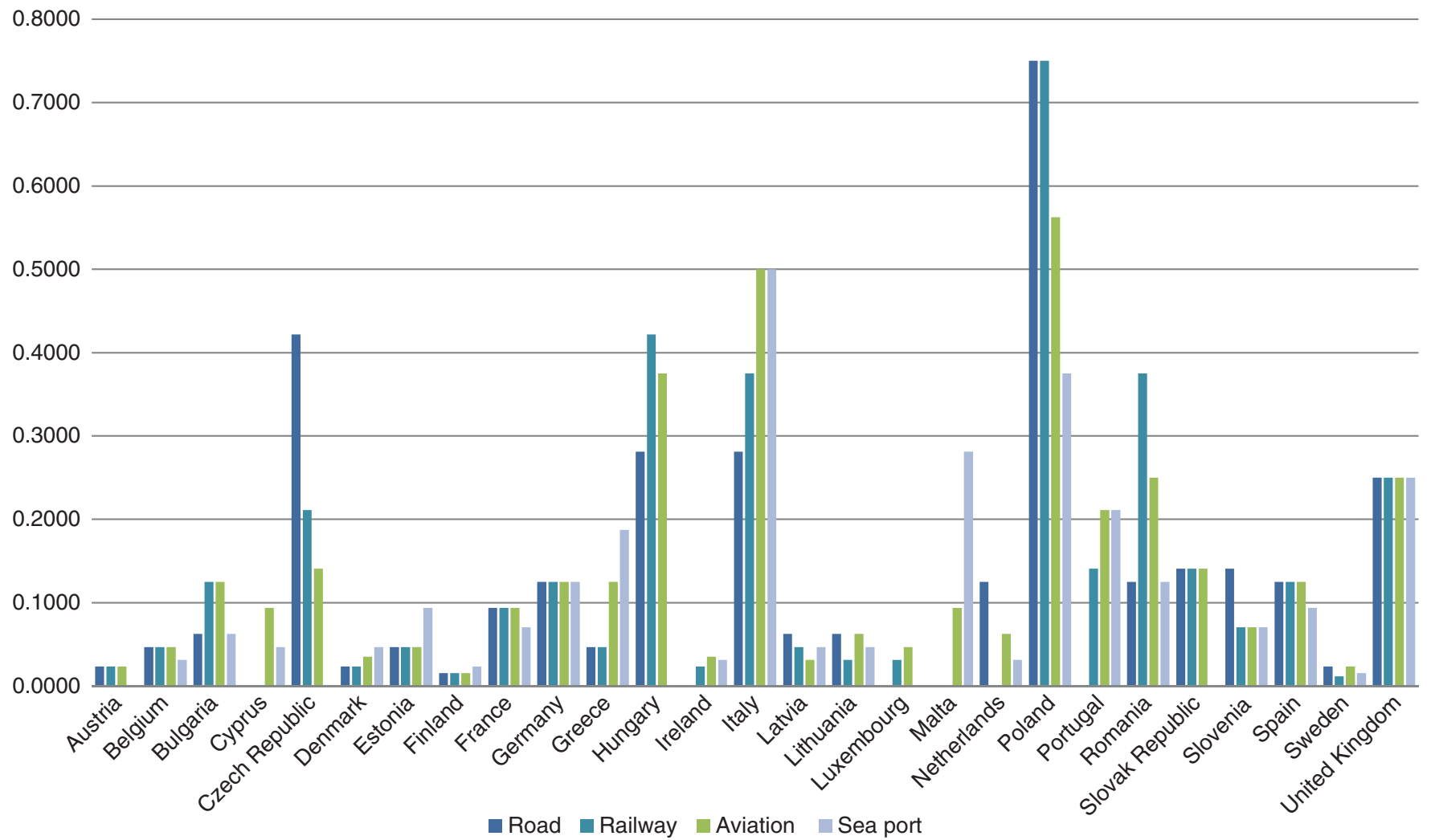

FIGURE 2 Vulnerability indicators for EU-27 passenger systems.

In the study, the vulnerabilities were derived for all motorized modes, divided into passenger and freight except inland waterways, assumed to be carrying only freight. Figure 2 shows the vulnerability indicators for the passenger systems of EU-27 member states.

Hazard was defined to be the probability of the outcome of the chain of events from weather phenomena to final consequences to society, including health (accidents), property (material), and delay consequences. Between a phenomenon and a consequence of the phenomenon there exists a direct causal connection, often physical in nature, such as falling trees or lightning striking. The actual consequence of the phenomenon takes place when the impacts affect the transportation system performance indicators, such as safety and timeliness. A phenomenon will occur with a certain probability, subjective or based on the historical data, in a geographical area.

Multiple paths with different probabilities may exist between a phenomenon and a consequence. With sufficiently large causal maps, it is an effort-consuming task to generate and analyze different paths to a particular consequence node. In EWENT, a method for filtering the most relevant set of paths was constructed, on the basis of Bellman's optimality principle [for detailed explanation of the applied method, see Molarius et al. (28)].

The outcome of these calculations was used to describe the natural hazard of different extreme weather events in each climatological area and directed to various transportation modes. According to the hazard indicator, $H_{I}$ would be

$H_{I}=f\left(P_{p} ; P_{i} ; P_{c}\right)$ where

$P_{p}=$ probability of phenomenon,

$P_{i}=$ probability of impacts, and

$P_{c}=$ probability of final consequences.

The final consequences stand for the end point of the concatenation of events starting from extreme weather phenomenon and ending with societal effects. These final consequences include $(a)$ time delays, $(b)$ infrastructure damages or maintenance cost increase, and $(c)$ accidents.

The hazard indicators varied between values of 0.01 to 0.99 depending on how strong the relationships were in the causal chains from weather phenomena to final consequences. The probability values were derived by several methods:

- Values obtained from the literature, either using statistical empirical materials or case studies;

- Expert assessments, experts representing different modes; and

- A combination of both.

The last mentioned was in reality the most common method, and the balance between empirical relationships and expert estimates varied.

An example of hazard indicators is given in Table 2. Probabilitybased hazard indicators have been calculated only for climate regions. Therefore, the hazard indicators stay constant from country to country within the same climate region. A more detailed description with examples can be found in Molarius et al. (28). 
TABLE 2 Hazard Indicators for Road Transport in Different Climate Regions

\begin{tabular}{lccc}
\hline Climate Region & Accidents & Maintenance & Delays \\
\hline North European & 0.10527 & 0.10527 & 0.08772 \\
Oceanic & 0.02339 & 0.02339 & 0.04964 \\
Temperate Central & 0.03509 & 0.03509 & 0.03210 \\
Temperate Eastern & 0.05848 & 0.05848 & 0.04874 \\
Mediterranean & 0.01170 & 0.05063 & 0.05049 \\
Mountainous & 0.08188 & 0.08188 & 0.04094 \\
\hline
\end{tabular}

\section{Extreme Weather Risk Indicator}

The risk is a product of natural hazard and vulnerability:

$\mathrm{EWRI}=f(H, V)=H \times V=H \times E \times S \times \mathrm{CC}_{\mathrm{inv}}$

which means operationally that risk is the product of selected maximum probabilities of consequences and ranking numbers of vulnerabilities. The hazards-leading to time delays, accidents or infrastructure damages, or increased maintenance needs-follow the climate zone division, where several countries belong to one climate region, whereas the vulnerabilities are calculated for each type of traffic (freight, passenger) in each mode and in each country.

For example, the hazard indicator for Finland's road accidents was $H_{r, a}=0.10527$, arising out of the probabilities of heavy snow leading to an increased accident risk, something that is shared by all countries in the North European climate region. The vulnerability indicator for the road passenger system was $V_{r, p}=0.0156$, as calculated previously.

The extreme weather risk indicator for road accident risks for passengers would then be

$\mathrm{EWRI}_{r, p, a}=H_{r, a} \times V_{r, p}=0.10527 \times 0.0156=0.00164$ which still indicates a very low value (see Figure 3 ). The hazard is relatively high, but the vulnerability of the subsystem is very low. Figure 3 illustrates the example. The risk indicator is a relative indicator, which means that it should be viewed and treated as a ranking system. It is not an absolute measure of risk.

Conceptually, EWRI can be depicted as shown in Figure 4. This combines empirical weather data with expert judgments or empirical knowledge on impacts and consequences, yielding hazard identification and quantification, then assesses the vulnerability of the system in question, and finally provides an estimate for the total risk.

\section{EXTREME WEATHER RISK INDICATORS FOR EU-27}

Earlier studies in the EWENT project showed that certain traffic modes in certain climate zones were more vulnerable than others when exposed to particular weather phenomena $(29,30)$. The outcome of these studies is compiled in Table 3.

In Figure 5, there are examples of risk indicators calculated from vulnerability indicators (combination of quality index of infrastructure, traffic density, population density, and coping capacity) and hazard indicators. The figure shows the overall situation in road transportation in Europe.

The figure shows all countries arranged by climate regions, so that some are even divided into two parts because they belong to two different areas. The first countries, from Cyprus (CY) to Spain (ES_M), belong to the Mediterranean area; countries from Belgium (BE) to Spain (ES_O) belong to the Oceanic region; from Austria (AT_Tc) to Denmark (DK_Tc) to the Temperate Central region; from Bulgaria (BG) to Romania (RO_Te) to the Temperate Eastern region; from France (FR_A) to Sweden (SE_A) to the Mountainous Region; and, finally, from Denmark (DK_NE) to Sweden (SE) to the Northern European region. Member states with high traffic densities, poor economic resources, and lower infrastructure quality dominate the high-risk group, as can be expected.

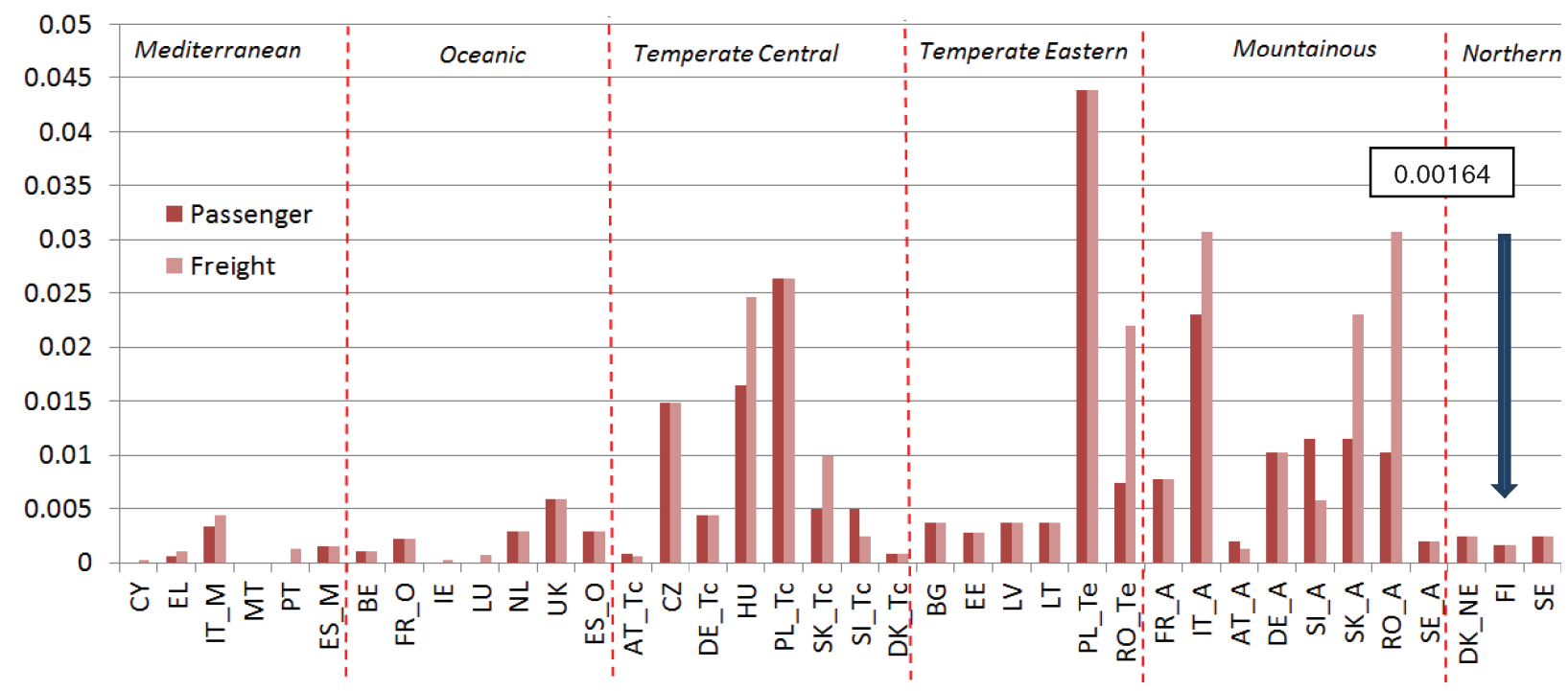

FIGURE 3 EWRIs for road passenger accidents. 


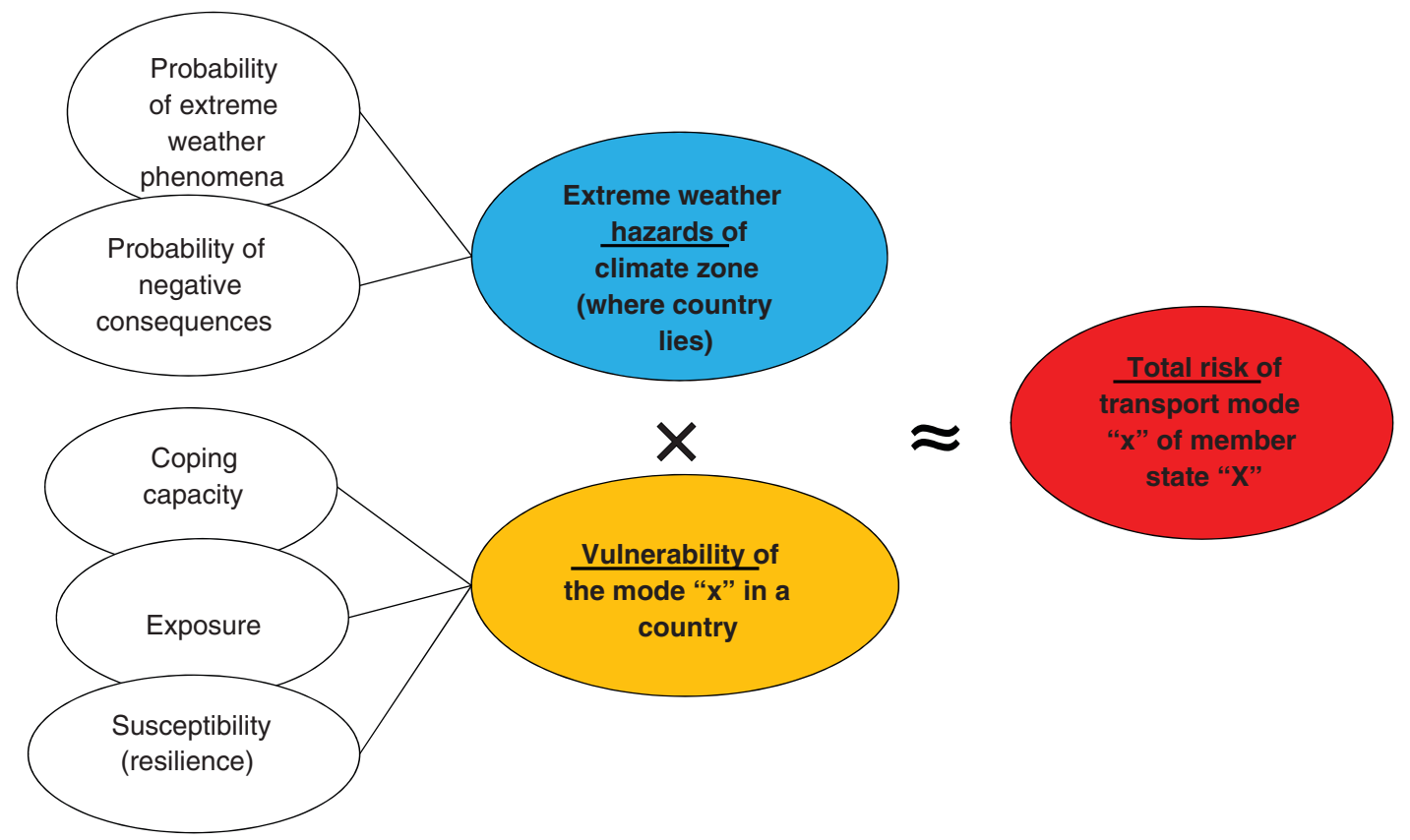

FIGURE 4 EWRI conceptual model.

\section{CONCLUSION AND DISCUSSION OF RESULTS}

The usefulness of EWRI remains to be seen, as few, if any, similar indicators for transportation systems that can be viewed as benchmarks have been publicly reported. Nonetheless, the devised EWRI is able to assist decision makers at the national and EU level in the prioritization of extreme weather risks within their jurisdiction. Of course, EWRI can work as a prioritization tool, but also as a ranking and benchmarking system, although it is unable to measure extreme weather risk in an absolute sense. However, the hazard analysis part relies mostly on empirical material (the probability of extreme weather events and causal effects), which makes it more than just a descriptive tool. Following from this, the empirical work behind hazard analysis may be quite substantial, making the use of EWRI not necessarily the most straightforward task.

The vulnerability part of EWRI is clearly more of a descriptive approach, but its advantage is that it is based on material and data that are relatively easily available, such as International Monetary Fund or Eurostat statistics. Data restrictions quickly reduce the utility of vulnerability analysis, however, when higher resolution is required (e.g., when different cities and municipalities are ranked within one country).

The overall approach of EWRI is based on mainstream risk and vulnerability assessment research, following for the most part the existing conceptual models developed earlier by other researchers. The novelty of EWRI lies in its application area (transportation) and wide use of both empirical and statistical data. EWRI was used to assess the hazards, vulnerabilities, and risks of extreme weather for the EU-27, but there is nothing that hinders its application, either in this form or a modified form, in other contexts besides Europe and transportation. The validation of EWRI should be done by comparing the risk indicators with empirical observations on experienced extreme weather damages.

\section{ACKNOWLEDGMENTS}

The European Commission is acknowledged for supporting this research through its 7th Framework Program. The EWENT consortium is acknowledged for fruitful cooperation and outstanding research efforts.

TABLE 3 The Most Vulnerable Transportation Modes for Extreme Weather According to Prior Analysis in EWENT

\begin{tabular}{|c|c|c|c|c|c|c|}
\hline Climate Region & Strong Winds & Heavy Snowfall & Heavy Precipitation & Cold Spells & Heat Waves & Blizzards \\
\hline Northern European region & Ss & Ro, Ra & Ro, Ra & Ro, Ra & - & Ro, Ra, Av, Ss \\
\hline Oceanic region & Ro, Ra, Ss & Ro, $\mathrm{Ra}$ & $\mathrm{Ro}, \mathrm{Ra}$ & Ro & - & Ro, Ra, Ss \\
\hline Mediterranean region & Ss & Ro & Ro & - & Ro, $\mathrm{Ra}$ & - \\
\hline Temperate Central European region & Ro, Ra, Av & Ro, Ra, Av & Ro, Ra, & IWT & IWT & Ro, Ra, Av, Ss \\
\hline Temperate Eastern European region & $\mathrm{Ro}, \mathrm{Ra}, \mathrm{Av}$ & $\mathrm{Ro}, \mathrm{Ra}, \mathrm{Av}$ & $\mathrm{Ro}, \mathrm{Ra}, \mathrm{Av}$ & IWT & Ra, IWT & Ro, Ra, Av, IWT \\
\hline Mountainous region & Av & Ro, $\mathrm{Ra}, \mathrm{Av}$ & Ro, Ra & IWT & IWT & Ro, $\mathrm{Ra}, \mathrm{Av}$ \\
\hline
\end{tabular}

NoTE: $\mathrm{Ss}=$ short sea shipping; $\mathrm{Ro}=\mathrm{road} ; \mathrm{Ra}=\mathrm{rail} ; \mathrm{Av}=$ aviation; - = not applicable; $\mathrm{IWT}=$ inland waterway. 


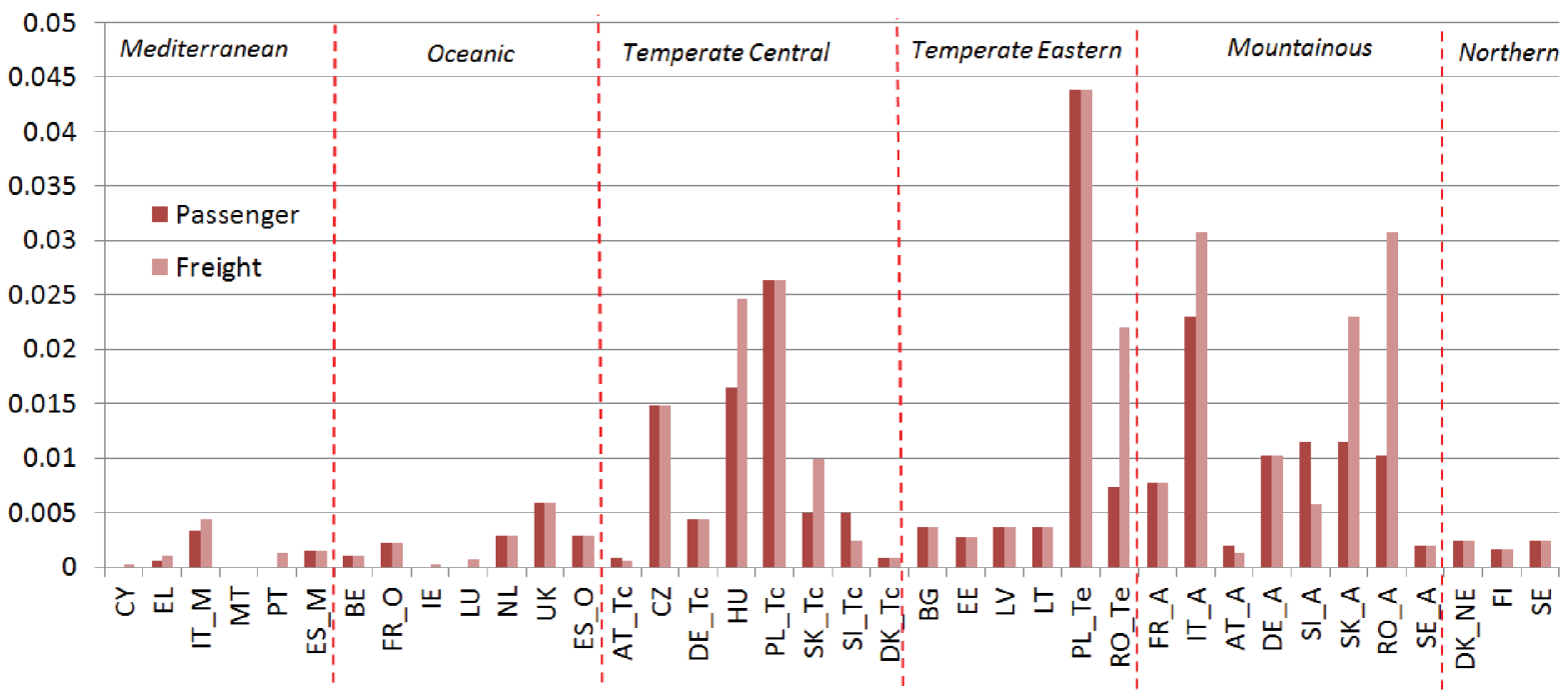

(a)

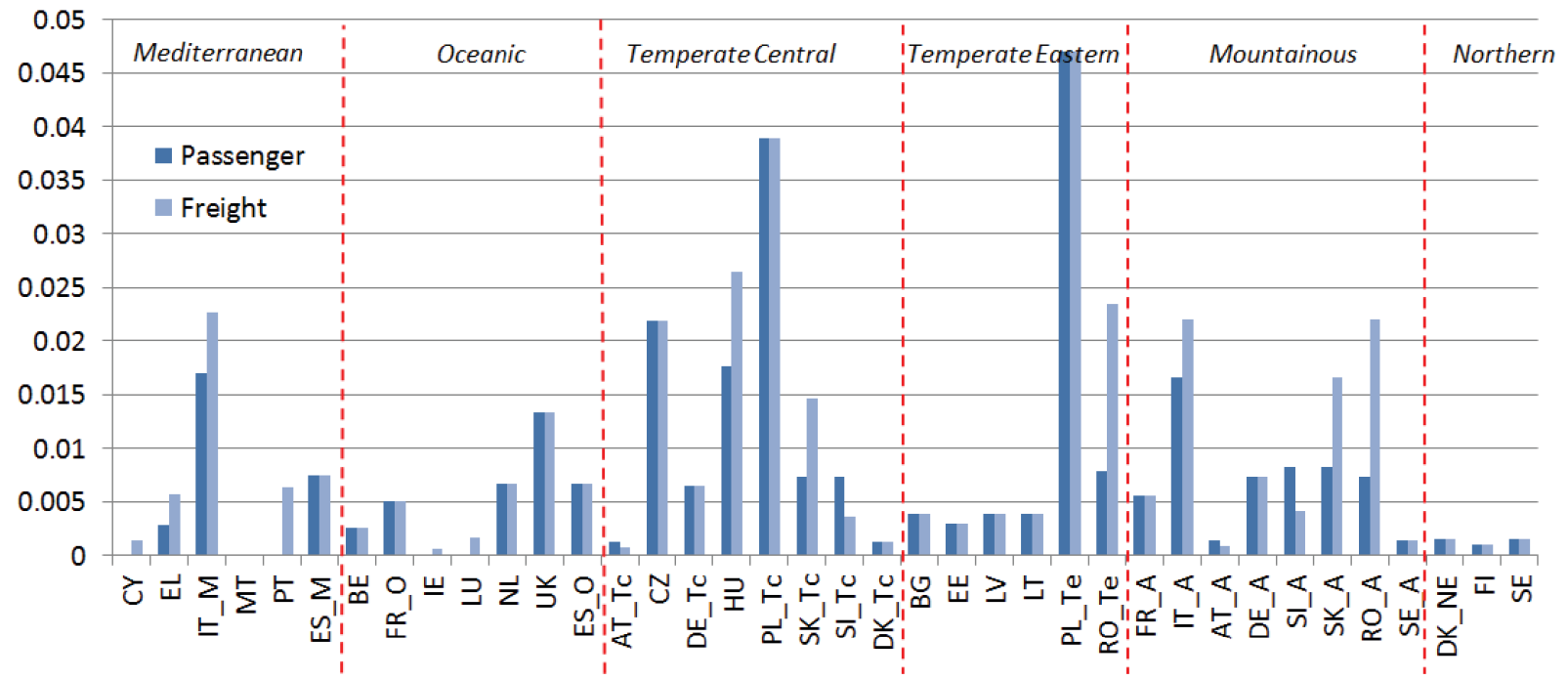

(b)

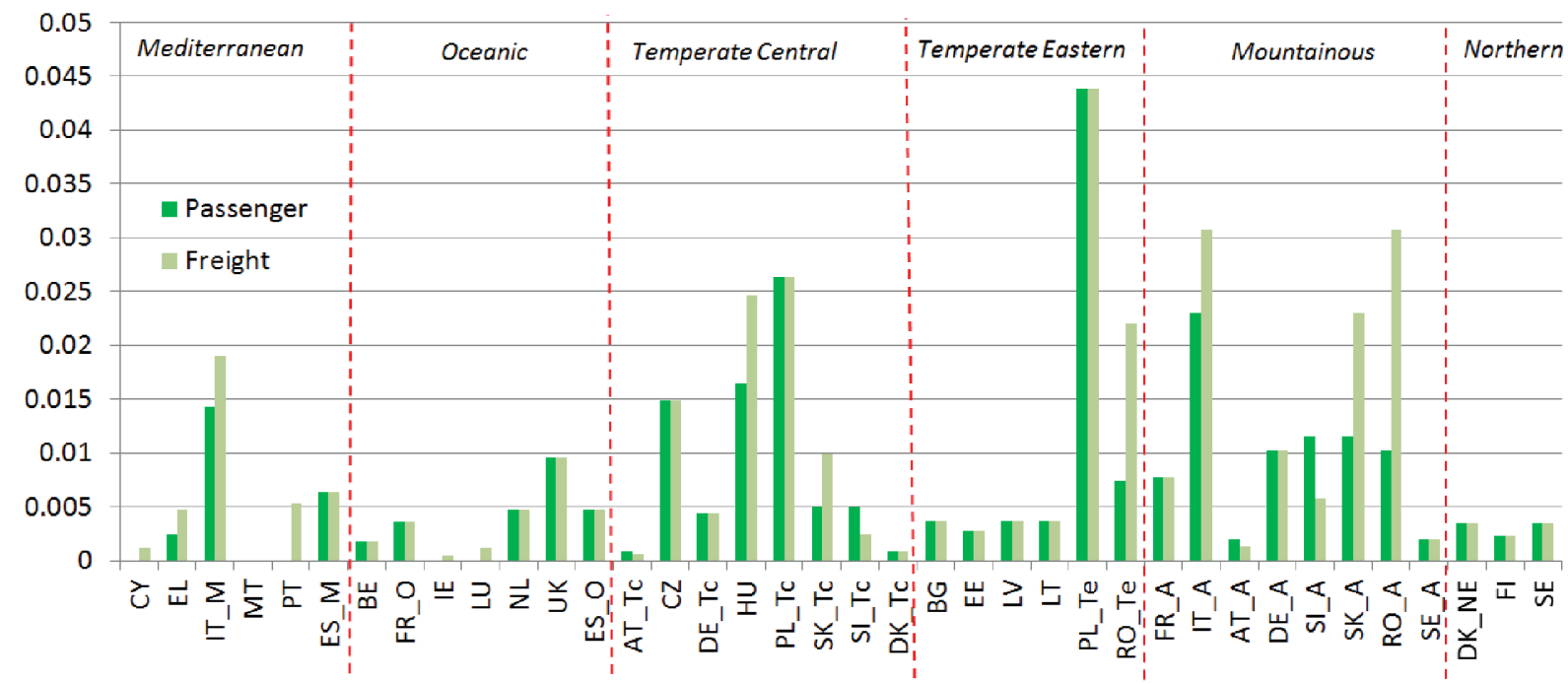

(c)

FIGURE 5 EWRIs for road transport in Europe: $(a)$ accident risk, $(b)$ delay risk, and $(c)$ risk for infrastructure damage and higher maintenance costs. 


\section{REFERENCES}

1. Vajda, A., H. Tuomenvirta, P. Jokinen, L. Makkonen, M. Tikanmäki, P. Groenemeijer, P. Saarikivi, S. Michaelides, and M. Papadakis. Probabilities of Adverse Weather Affecting Transport in Europe: Climatology and Scenarios up to the 2050s. EWENT Project Deliverable 2.1, Finnish Meteorological Institute, Helsinki, Finland, Aug. 19, 2011.

2. Taylor, M. A. P., and G. M. D'Este. Transport Network Vulnerability: A Method for Diagnosis of Critical Locations in Transport Infrastructure Systems. In Critical Infrastructure: Reliability and Vulnerability. Springer, Berlin, 2007, pp. 9-30.

3. Sohn, J., J. T. Kim, G. J. Hewings, J. S. Lee, and S.-G. Jang. Retrofit Priority of Transport Network Links Under an Earthquake. Journal of Urban Planning and Development, Vol. 129, No. 4, 2003, pp. 195-210.

4. Schulz, C. Identification of Critical Transport Infrastructures. 8th Forum DKKV/CEDIM. Disaster Reduction in Climate Change. Karlsruhe University, Karlsruhe, Germany, 2007.

5. Nicholls, R. J., S. Hanson, C. Herweijer, N. Patmore, S. Hallegatte, J. Corfee-Morlot, Jean Chateau, and Robert Muir-Wood. Ranking Port Cities with High Exposure and Vulnerability to Climate Extremes: Exposure Estimates. OECD Environment Working Papers, No. 1, OECD Publishing, 2008.

6. Riccardo, E., C. Doll, S. Klug, I. Partzsch, N. Sedlacek, N. Nesterova, J. Kiel, L. Rudzikaite, A. Papanikolaou, and V. Mitsakis. Deliverable 2, Vulnerability of Transport Systems. Main Report. 2011. http://www. weatherproject.eu/weather/downloads/Deliverables/WEATHER_ Deliverable-2_main-report_20110614.pdf.

7. Purdy, G. ISO $31000: 2009$ : Setting a New Standard for Risk Management. Risk Analysis, Vol. 30, No. 6, 2010, pp. 881-886.

8. Leitch, M. ISO 31000:2009-The New International Standard on Risk Management. Risk Analysis, Vol. 30, No. 6, 2010, pp. 887-892.

9. Lough, K. G., R. Stone, and I. Y. Turner. Function Based Risk Assessment; Mapping Function to Likelihood. Proc., International Design Engineering Technical Conferences and Computers and Information in Engineering Conference, Long Beach, Calif., 2005.

10. Habegger, B. (ed.). Risk Analysis and Management in a Dynamic Landscape. In International Handbook on Risk Analysis and Management: Professional Experiences. Center for Security Studies, Zurich, Switzerland, 2008. www.crn.ethz.ch.

11. Gibson, S. B. The Quantitative Measurements of Process Safety. Institution of Chemical Engineers, Symposium Series 49, 1977.

12. Abrahamsen, E. B., and T. Aven. On the Consistency of Risk Acceptance Criteria with Normative Theories for Decision-Making. Reliability Engineering and System Safety, Vol. 93, 2008, pp. 1906-1910.

13. Head, G. An Alternative to Defining Risk as Uncertainty. Journal of Risk and Insurance, Vol. 34, No. 2, 1967, pp. 205-214.

14. Denenburg, H. S., R. D. Eilers, J. Melone, and J. Zelten. Risk and Insurance, 2nd ed. Prentice Hall, Englewood Cliffs, N.J., 1974.

15. Füssel, H.-M. Vulnerability: A Generally Applicable Conceptual Framework for Climate Change Research. Global Environmental Change, Vol. 17, No. 2, 2007, pp. 155-167.

16. Cutter, S. L. Living with Risk: The Geography of Technological Hazards. Edward Arnold, London, 1993, p. 214.
17. de León, J. C. V. Vulnerability: A Conceptual and Methodological Review. United Nations University, Institute for Environment and Human Security. Publication Series of UNU-EHS, No. 4, 2006. http://www.ehs.unu.edu/ file/get/3904.

18. Walker, G., H. Deeming, C. Margottini, and S. Menoni. Introduction to Sustainable Risk Mitigation for a More Resilient Europe. In Inside Risk: A Strategy for Sustainable Risk Mitigation (S. Menoni and C. Margottini, eds.), Springer-Verlag, New York, 2011, pp. 1-22.

19. Alexander, D. Confronting Catastrophe. Terra, Hertfordshire, United Kingdom, 2000.

20. Villagrán, J. C. La Naturaleza de los Riesgos, un Enfoque Conceptual. Serie: Aportes para el Desarrollo Sostenible. CIMDEN, Guatemala, 2002.

21. Dilley, M., R. Chen, U. Deichmann, A. Lerner-Lam, and M. Arnold Natural Disaster Hotspots: A Global Risk Analysis. Disaster Risk Management Series No. 5, The World Bank, Washington, D.C., 2005.

22. White, P., M. Pelling, K. Sen, D. Seddon, S. Russel, and R. Few. Disaster Risk Reduction: A Development Concern. A Scoping Study on Links Between Disaster Risk Reduction, Poverty, and Development. Department for International Development, London, 2005.

23. CEPS. Protecting Critical Infrastructure in the EU. CEPS Task Force Report. Center for European Policy Studies, Brussels, Belgium, 2010 http://www.ceps.be/book/protecting-critical-infrastructure-eu.

24. Cutter, S. L., B. J. Boruff, and W. L. Shirley. Social Vulnerability to Environmental Hazards. Social Science Quarterly, Vol. 84, No. 2, 2003 , pp. 242-261.

25. Eurostat, 2012. http://epp.eurostat.ec.europa.eu/portal/page/portal/ eurostat/home.

26. Schwab, K. The Global Competitiveness Report 2011-2012. World Economic Forum, Geneva. http://www3.weforum.org/docs/WEF_GCR Report_2011-12.pdf.

27. IMF World Economic Outlook. U.S. Agency for International Development, 2012.

28. Molarius, R., P. Leviäkangas, A.-M. Hietajärvi, M. Nokkala, J. Rönty, V. Könönen, Z. Zulkarnain, K. Oiva, S. Mäensivu, M. Kreuz, T. Mühlhausen, J. Ludvigsen, P. Saarikivi, A. Vajda, H. Tuomenvirta, S. Athanasatos, M. Papadakis, S. Michaelides, N. Siedl, J. Schweighofer, K. Riemann-Campe, and P. Groenemeijer. D5.1 Weather Hazards and Vulnerabilities for the European Transport System-A Risk Panorama. EWENT Project Deliverable, VTT Technical Research Center of Finland, Oulu, Finland, July 2012.

29. Leviäkangas, P., A. Tuominen, R. Molarius, and H. Kojo (eds.). Extreme Weather Impacts on Transport Systems. EWENT Deliverable D1, VTT Working Papers 168, VTT Technical Research Center of Finland, Oulu, Finland, 2011.

30. Kreuz, M., T. Mühlhausen, J. Bläsche, J. Schweighofer, P. Leviäkangas, R. Molarius, M. Nokkala, S. Athanasatos, S. Michaelides, M. Papadakis, and J. Ludvigsen. EWENT D3-Consequences of Extreme Weather. DLR Forschungsbericht 2012-03. German Aerospace Center, Stuttgart, Germany.

The Surface Transportation Weather Committee peer-reviewed this paper. 